\title{
Resíduos sólidos urbanos e a Agenda 2030: Uma análise das ações realizadas pelo município de São José do Seridó/RN
}

\author{
Urban solid waste and the 2030 Agenda: An analysis of actions taken by the municipality of São \\ José do Seridó/RN
}

Residuos sólidos urbanos y la Agenda 2030: Un análisis de las acciones llevadas a cabo por el municipio de São José do Seridó/RN

\author{
Kaio Luís de Azevêdo Santos \\ ORCID: https://orcid.org/0000-0002-5904-8549 \\ Faculdade Católica Santa Teresinha, Brasil \\ E-mail: kaioluis@hotmail.com \\ Josimar Araujo de Medeiros \\ ORCID: https: //orcid.org/0000-0002-9554-1146 \\ Faculdade Católica Santa Teresinha, Brasil \\ E-mail: josimarsaojosedoserido@gmail.com \\ Luziana Maria Nunes de Queiroz \\ ORCID: https://orcid.org/0000-0002-0365-3029 \\ Universidade Federal do Rio Grande do Norte, Brasil \\ E-mail: luziana65@hotmail.com \\ Priscilla Pimentel Diogenes Gois de Araujo \\ ORCID: https://orcid.org/0000-0002-7347-0746 \\ Universidade Federal do Rio Grande do Norte, Brasil \\ E-mail: priscilladiogenes@gmail.com \\ Deylane Freitas Fontes Júnior \\ ORCID: https://orcid.org/0000-0003-4838-6080 \\ Universidade Federal do Rio Grande do Norte, Brasil \\ E-mail: deylanefreitas2@gmail.com
}

\begin{abstract}
Resumo
As ações realizadas pelo ente municipal de São José do Seridó/RN, no tocante a gestão de resíduos sólidos na municipalidade e sua correlação com os objetivos traçados na Agenda 2030, elaborada e ratificada pelos países signatários da Organização das Nações Unidas (ONU), compõe o eixo de análise do presente artigo. Para melhor entendimento dessa relação, adotou-se como objetivo geral compreender a contribuição das ações de gestão de resíduos sólidos urbanos realizadas pelo município de São José do Seridó/RN, em atendimento aos objetivos da Agenda 2030 da ONU. Feito isso, partiu-se para o desdobramento da temática por intermédio dos objetivos específicos a seguir: (i) identificar as ações realizadas pelo município para mitigação dos resíduos sólidos urbanos, (ii) entender a relevância das ações efetuadas para suavizar o impacto causado ao meio ambiente e (iii) relacionar as ações desenvolvidas aos objetivos da Agenda 2030. Para consecução dos objetivos traçados, adotou-se uma metodologia de cunho exploratório e descritivo, com realização de um aprofundamento bibliográfico e coleta empírica de dados, por meio de uma pesquisa participante estruturada. A análise dos dados oriundos da pesquisa segue a abordagem qualitativa. O presente estudo se justifica pelo fato do lixo urbano representar um problema ainda com poucas soluções práticas. Por isso, grande parte dos municípios brasileiros não conseguem atender plenamente o que está posto na Política Nacional de Resíduos Sólidos. Por fim, verifica-se que a entidade municipal realiza atividades que alinhem comprometimento e responsabilidade sustentável, de maneira a gerar um menor impacto ambiental conseguindo atender parcialmente alguns ODS.
\end{abstract}

Palavras-chave: Gestão ambiental; Resíduos sólidos urbanos; Agenda 2030; São José do Seridó.

\begin{abstract}
The actions carried out by the municipal entity of São José do Seridó/RN, regarding the management of solid waste in the municipality and its correlation with the objectives outlined in the 2030 Agenda, prepared and ratified by the signatory countries of the United Nations (UN), comprise the axis of analysis in this paper. For a better understanding of this relation, it was adopted as a general objective to understand the contribution of urban solid waste management actions carried out by the municipality of São José do Seridó/RN, in compliance with the objectives of the UN 2030 Agenda. Once this was done, the theme was developed through the following specific objectives: (i) identifying the actions taken by the municipality to mitigate urban solid waste, (ii) understanding the relevance of the actions taken to
\end{abstract}


mitigate the impact caused by environment and (iii) relating the actions developed to the objectives of the 2030 Agenda. In order to achieve the objectives outlined, an exploratory and descriptive methodology was adopted, with a bibliographic deepening and empirical data collection, through a structured participant research. The analysis of the data from the research follows the qualitative approach. The present study is justified by the fact that urban waste is still a problem with few practical solutions. For this reason, most Brazilian municipalities are unable to fully meet the requirements of the National Solid Waste Policy. Finally, it appears that the municipal entity carries out activities that align commitment and sustainable responsibility, in order to generate less environmental impact, managing to partially meet some SDG.

Keywords: Environmental management; Urban solid waste; 2030 Agenda; São José do Seridó.

\section{Resumen}

Las acciones llevadas a cabo por el municipio municipal de São José do Seridó/RN, en relación con la gestión de residuos sólidos en el municipio y su correlación con los objetivos esbozados en la Agenda 2030, elaboradas y ratificadas por los países signatarios de las Naciones Unidas (ONU), componen el eje de análisis de este artículo. Para comprender mejor esta relación, el objetivo general era comprender la contribución de las acciones municipales de gestión de residuos sólidos llevadas a cabo por el municipio de São José do Seridó/RN, en cumplimiento de los objetivos de la Agenda 2030 de las Naciones Unidas. Una vez hecho esto, comenzamos a desarrollar el tema a través de los siguientes objetivos específicos: (i) identificar las acciones llevadas a cabo por el municipio para mitigar los residuos sólidos urbanos, (ii) comprender la relevancia de las acciones tomadas para suavizar el impacto causado al medio ambiente y (iii) relacionar las acciones desarrolladas con los objetivos de la Agenda 2030. Para lograr los objetivos esbozados, se adoptó una metodología exploratoria y descriptiva, con una profundización bibliográfica y una recopilación empírica de datos, a través de una investigación estructurada de los participantes. El análisis de los datos de la investigación sigue el enfoque cualitativo. El presente estudio se justifica por el hecho de que los residuos urbanos representan un problema todavía con pocas soluciones prácticas. Por lo tanto, la mayoría de los municipios brasileños no pueden cumplir plenamente con lo que se pone en la Política Nacional de Residuos Sólidos. Por último, se verifica que la entidad municipal realice actividades que alineen el compromiso y la responsabilidad sustentable, con el fin de generar un menor impacto ambiental, logrando cumplir parcialmente con algunos ODS.

Palabras clave: Gestión ambiental; Residuos sólidos municipales; Agenda 2030; São José de Seridó.

\section{Introdução}

O município de São José do Seridó/RN está localizado no interior do estado do Rio Grande do Norte (Figura 1), mais precisamente na Região do Seridó, situado no semiárido do nordeste brasileiro. Possui, segundo dados estatísticos do Instituto Brasileiro de Geografia e Estatística - IBGE (2019) uma população de 4.231 (quatro mil, duzentos e trinta e um) habitantes e está localizado há uma distância de $245 \mathrm{~km}$ da capital do estado, a cidade de Natal/RN.

Figura 1. Mapa do estado do Rio Grande do Norte com destaque para o município de São José do Seridó.

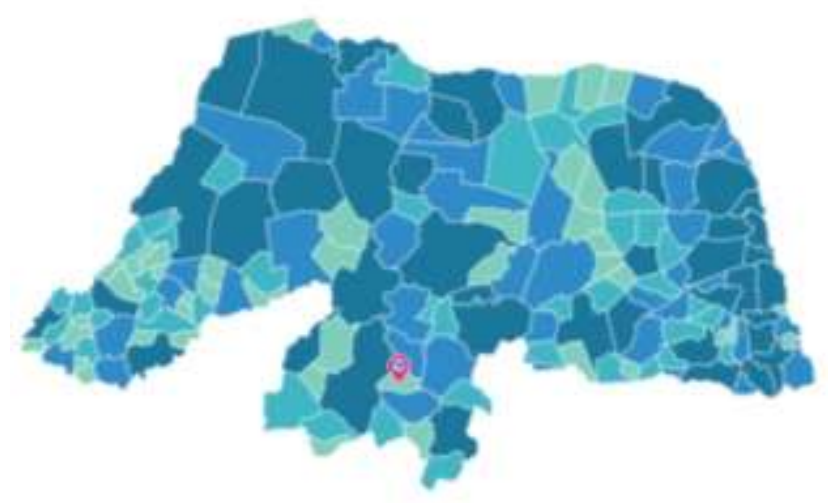

Fonte: https://cidades.ibge.gov.br/brasil/rn/sao-jose-do-serido/panorama.

A dificuldade de união entre as entidades federativas para a criação e implementação de políticas públicas está arraigada nas esferas administrativas e políticas brasileiras. Isso pode ser observado nas relações entre as instâncias formuladoras de políticas e diretrizes nacionais e as executoras em nível de localidade. 
Conforme a legislação atual, os municípios possuem a responsabilidade quanto ao manejo dos resíduos sólidos urbanos (RSU) e a limpeza das cidades. A legislação federal que estabelece a Política Nacional de Resíduos Sólidos (PNRS), Lei $n^{\circ} 12.305 / 2010$, institui objetivos e princípios, um fato histórico que marca a gestão de RSU no país.

Porém, ao se observar a situação dos municípios, segundo Maiello (2018) em sua grande maioria, encontram-se desarticulados e com poucos recursos disponíveis para a implantação de ações que impactem no cumprimento da legislação. Diante disso, eles vêm sofrendo de um ordenamento duplo, ora estadual, ora nacional, sem que haja para isso um maior subsídio federal para implementação de políticas de abrangência local.

Logo, devido aos problemas ambientais, oriundos do uso desordenado dos recursos naturais, nasce a inquietação com a situação ambiental, a qual advém não apenas do uso indevido de recursos, como também pelo descarte inapropriado de resíduos com potencial de provocar danos ao meio ambiente.

A produção de resíduos sólidos vem crescendo em todas as regiões do Brasil (Gouveia, 2012), mas parte considerável desses resíduos não possui destinação sanitária correta. Ainda que tenha existido um avanço nos últimos anos com relação à utilização, por parte dos entes municipais, de aterros controlados. Porém, ainda existe um elevado quantitativo de áreas que servem de depósito a céu aberto, os conhecidos lixões. Por isso, é necessária a adoção de medidas para readequação do comportamento da sociedade diante de questões dessa natureza.

Assim, a cidade de São José do Seridó/RN, desponta como um caso à parte, onde a gestão municipal trata de desenvolver ações que buscam a mitigação do impacto ambiental causado pelos resíduos sólidos urbanos. Essas ações têm gerado não só impacto para o convívio social em um ambiente mais limpo, como também tem oportunizado a destinação adequada de determinados resíduos, assim como proporcionado a geração de trabalho e renda a famílias de Catadores de Materiais Recicláveis (CMRs).

As ações realizadas pelo município estão em consonância com os objetivos traçados pela Agenda 2030, da Organização das Nações Unidas (Brasil, 2019), que busca promover o desenvolvimento sustentável por meio da implantação de uma agenda universal com objetivos e metas a serem desenvolvidas pelos países signatários, no qual o Brasil faz parte. A Agenda 2030 traça metas em áreas consideradas cruciais para o desenvolvimento da humanidade visando os quinze anos subsequentes à sua elaboração, tratada no ano de 2015.

\subsection{Objetivos de Pesquisa}

O presente artigo busca compreender a contribuição das ações de gestão de resíduos sólidos urbanos realizadas pelo município de São José do Seridó/RN em atendimento aos objetivos da Agenda 2030 da ONU. Para tanto, procurou-se (i) identificar as ações realizadas pelo município para mitigação dos resíduos sólidos urbanos, (ii) entender a relevância das ações efetuadas para suavizar o impacto causado ao meio ambiente e (iii) relacionar as ações desenvolvidas aos objetivos da agenda 2030.

\section{Metodologia}

O procedimento de estudo adotado na presente pesquisa trata-se, com relação aos objetivos, de uma pesquisa de cunho exploratório e descritivo. Essa tipologia de análise tem como fundamento tratar os acontecimentos em estudo, por meio de pareceres, opiniões, julgamentos e notas oriundas da visualização empírica e da fundamentação teórica (Matias-Pereira, 2019). A pesquisa foi realizada por intermédio de uma verificação bibliográfica inicial, como parte essencial para a afirmação do sustentáculo teórico necessário as análises e discussões contidas nesse trabalho para a interpretação das observações de campo e atendimento aos objetivos propostos.

A pesquisa bibliográfica permite o aprofundamento da pesquisa ao realizar o estudo criterioso de produções, textos e 
resultados de investigações já desenvolvidas por outros pesquisadores, conforme visto em suas obras (Medeiros, 2019). A observância de referências constitui-se uma das nascentes de pesquisa e aquisição de conceitos importantes para análise da problemática exposta. O montante das contribuições dos autores e escritores lidos se junta aos dados advindos da visualização no campo. A ponderação sobre essa relação, campo/teoria, origina a formulação de contribuições e reflexões inovadoras sobre o tema abordado.

As fases para o ordenamento da averiguação científica seguiram a ordem adiante: arrolamento do conteúdo bibliográfico; eleição de textos para a fundamentação da teoria; realização de leituras, ficha e reserva dos dados e conteúdos significantes à confecção e elaboração textual; visita à cidade para observação empírica das ações realizadas pela prefeitura municipal.

A coleta de dados "in loco" iniciou-se com uma observação empirista. Adotou-se a metodologia de observação participante estruturada, onde os pesquisadores buscaram correlacionar às ações de gestão de resíduos sólidos adotadas pelo município em análise com os objetivos constantes na Agenda 2030 da Organização das Nações Unidas (ONU). Essa metodologia procura compreender a realidade da sociedade e suas múltiplas relações, complexas e subjetivas (Gil, 2019). Assim, permite-se a descrição e definição do caso selecionado, por intermédio da coleta de dados não gerais, mas que norteiem a análise da problemática em discussão.

A utilização dessa tipologia metodológica admite a adoção de uma abordagem qualitativa, com o intuito de buscar compreensões e significações para melhor apreender a relação conceitual teórica e suas relações e implicações com os dados observados em campo. A apreciação e interpretação das situações apresentadas permite identificar as variáveis a inferir no fenômeno observado (Medeiros, 2021). Diante disso, o investigador passa a possuir melhores meios para a compreensão de suas observações de campo.

O emprego da abordagem qualitativa abarca a análise das variantes identificadas empiricamente. Com isso, o observar qualitativo (Pereira, et al., 2018), procura compreender o caminhar da pesquisa e a verificação dos dados interpretados ao olhar das teorias e conhecimentos correntes no ambiente científico. A apreciação qualitativa comporta a compreensão e entendimento dos dados recolhidos nas observações de campo e o correlacionamento das situações identificadas com os conhecimentos consolidados e catalogados na área de discussão.

Logo, nota-se que a pesquisa de cunho qualitativa (Bernardes, 2018) se forma de uma abordagem metodológica de investigação que situa o estudioso em uma situação de mundo através de um conjunto de métodos interpretativos que norteiam e levam a uma crítica flexível e detalhada para o entendimento e compreensão da situação em discussão.

\section{Resultados e Discussão}

O lixo ${ }^{1}$ urbano, seja doméstico ou industrial, consiste em um problema ainda com poucas soluções práticas. Por isso, na maioria dos municípios brasileiros esses dejetos são despejados à revelia em locais inapropriados (Schueler, 2018) com sérios problemas para a paisagem ${ }^{2}$, além dos prejuízos provocados à biota ${ }^{3}$. No local onde o lixo é depositado, ocorre a eliminação da cobertura vegetal. Dessa forma, os animais silvestres que frequentam esses locais terminam por ingerir o conteúdo encontrado, como plástico e outros materiais contaminados, o que pode causar doenças e até a morte. Para o homem, segundo Silva (2011), o lixo segue como um grande vilão na poluição dos recursos hídricos, pois além de contaminar o solo e

\footnotetext{
1 “O lixo, também conhecido como resíduo sólido, é todo e qualquer material resultante da atividade do homem ou da dinâmica da natureza que é descartado por não estar [...] mais em condições de uso” (Brasil, 2013).

2 "Esta pode ser definida como o domínio do visível, aquilo que a vista abarca. Não é formada apenas de volumes, mas também de cores, movimentos, odores, sons, etc" (Santos, 1988, p. 61).

3 "Nome que se dá às características da vida animal e vegetal de uma determinada região" (Barbosa, 1979, p. 96).
} 
as águas subterrâneas, as enxurradas transportam para dentro das coleções de água o chorume ${ }^{4}$ e outras substâncias perigosas.

\subsection{Ações de Gestão de Resíduos Sólidos Realizadas Pelo Município de São José do Seridó/RN}

No município de São José do Seridó/RN não acontece diferente - o lixo antes era despejado à revelia, repercutindo negativamente sobre os bens naturais e atividades humanas. A partir do ano de 2009, como resultado de um projeto de intervenção do governo municipal, essa prática foi modificada. Todo o lixo da zona urbana e parte do da zona rural passou a ser acondicionado em um Aterro Controlado (Lisboa, et al, 2020), que consiste em uma obra de engenharia que busca receber e acomodar os resíduos em um espaço menor, com mínimos riscos de danos à saúde da população e ao meio ambiente. Esse tipo de acondicionamento necessita da compactação de resíduos no solo, em espécies de camadas que são de tempos em tempos cobertas com solo, ou algum material inerte. O Aterro Controlado do município de São José do Seridó encontra-se situado em uma área de terreno cristalino ${ }^{5}$, de baixa permeabilidade. Para isso, foram feitas trincheiras com paredes de proteção para impedir que a água das enxurradas seja misturada com o lixo, conforme a Figura 2 a seguir.

Figura 2. Antigo lixão da cidade e trincheira aberta para acondicionar o lixo em aterro controlado.

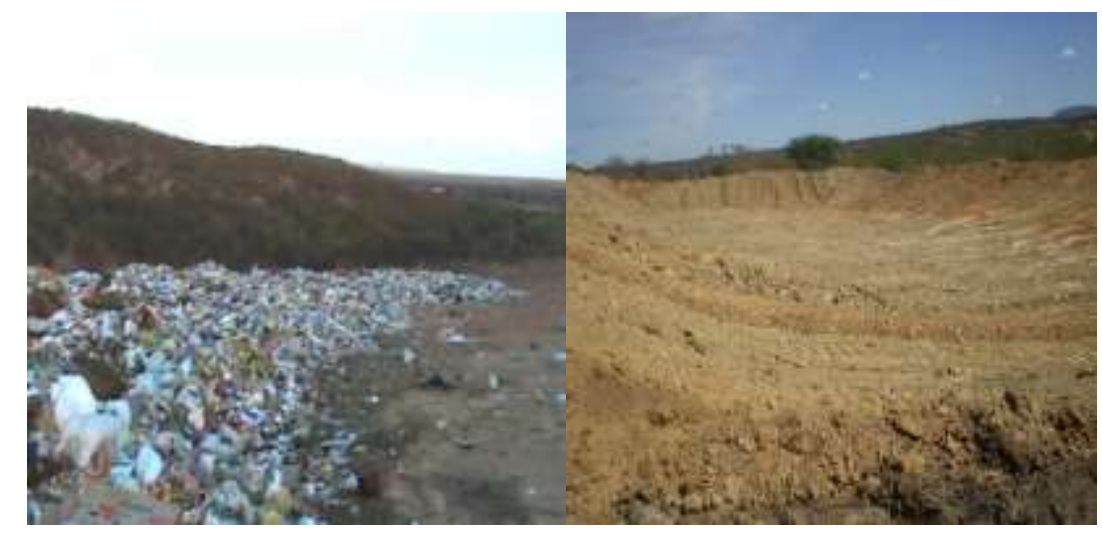

Fonte: Arquivo pessoal dos autores.

À medida em que os resíduos vão sendo depositados, uma camada de solo é colocada como cobertura, como pode ser visto na Figura 3. Importante salientar que para o primeiro material de cobertura em geral são utilizados resíduos de construção civil. Para recuperar a área devastada para construção do aterro controlado o município realizou o reflorestamento do espaço já utilizado no aterro com uso de plantas nativas. Dez anos após o início das atividades do aterro, no ano de 2009, um bosque de plantas nativas já encobre parte da área que vem sendo utilizada. Isso pode ser atestado conforme visualização da Figura 4.

\footnotetext{
${ }^{4}$ Segundo Giordano, Barbosa Filho \& Carvalho (2011) "o chorume é [...] o produto da lixiviação dos resíduos urbanos nas condições de disposição. [...] O chorume pode contaminar as águas superficiais como também as águas subterrâneas, além de degradar o solo e a vegetação" (p. 2)

5 O terreno Cristalino Potiguar está contido na faixa Seridó, que constitui um dos diversos cinturões orogênicos da Província Borborema (Almeida et al., 1977).
} 
Figura 3. Cobertura do lixo sendo realizada no Aterro Controlado.

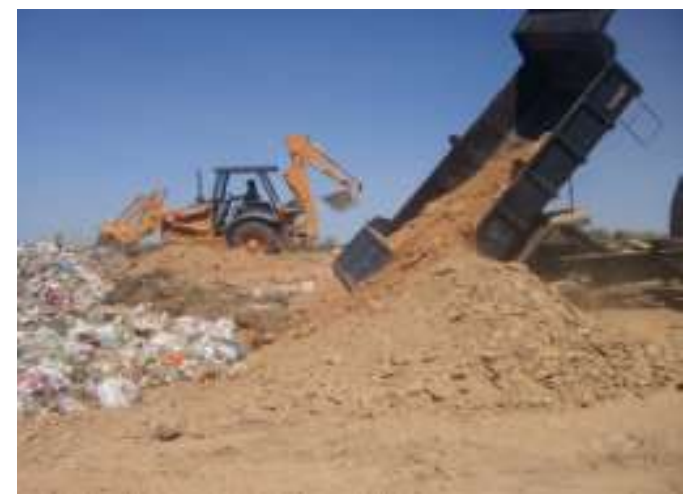

Fonte: Arquivo pessoal dos autores.

Figura 4. Área do aterro controlado reflorestada.

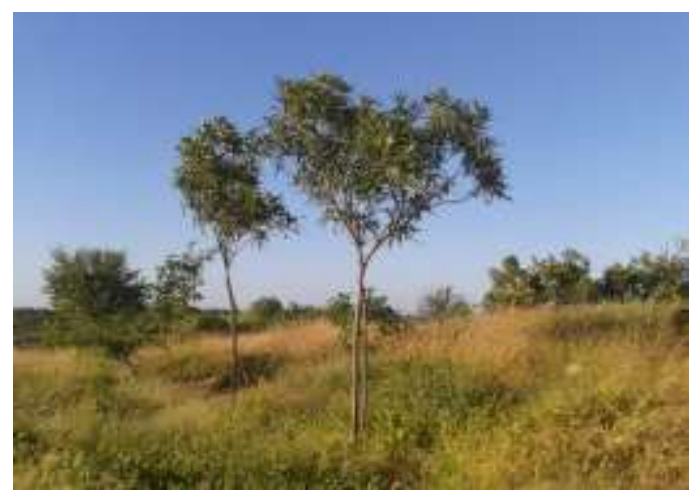

Fonte: Arquivo pessoal dos autores.

Com essa ação, praticamente a queima de lixo na municipalidade foi neutralizada. Tendo continuado apenas nos resíduos oriundos da poda das plantas urbanas se empregava o fogo na queima. Importante destacar que em paralelo a implantação do aterro controlado, a coleta seletiva também passou a ser uma realidade. A coleta seletiva (Conke \& Nascimento, 2018), muito lembrada pela separação do material que pode ser reciclado, não consiste apenas em uma forma diferente de recolher o lixo, mas um ciclo que se inicia no momento do descarte e se finaliza com o resíduo reciclável sendo utilizado em um processo de produção e/ou beneficiamento.

Para isso, a municipalidade com o apoio da população implantou um conjunto de ações no intuito de reduzir o volume de lixo que chega ao aterro controlado. Uma das medidas é a separação do papelão por parte das fontes geradoras. O material é depositado junto aos estabelecimentos para coleta e comercialização por parte dos Catadores de Materiais Recicláveis (CMRs), conforme Figura 5. 
Figura 5. Coleta de papelão pelas ruas e o carregamento direto para fábrica de reciclagem no Estado da Paraíba.

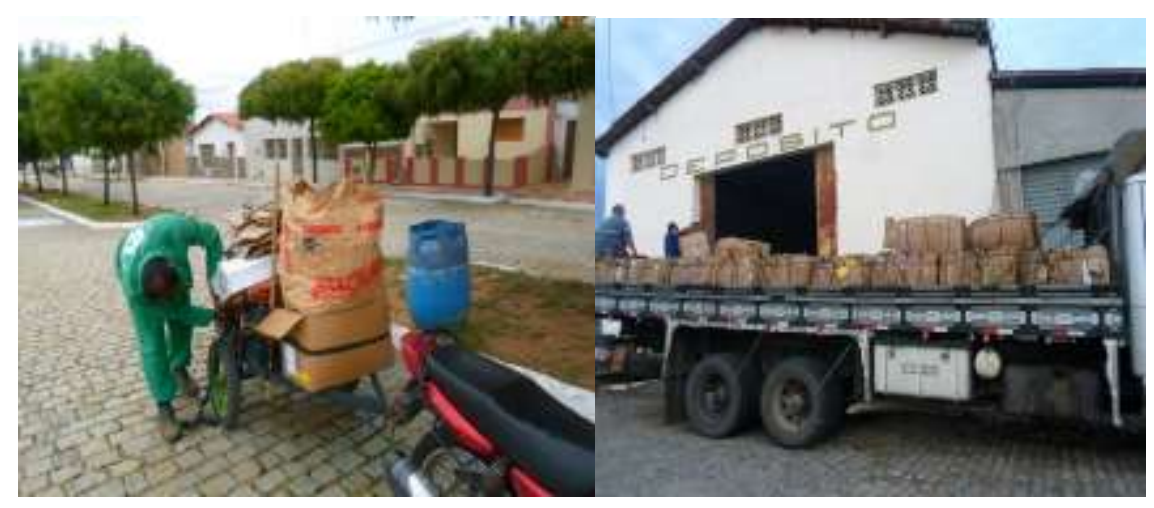

Fonte: Arquivo pessoal dos autores.

Para a coleta de plásticos e de metais, cerca de 30 tambores foram distribuídos nas ruas e nas repartições públicas. A comunidade se encarrega de depositar o lixo nos tambores de coleta para posterior coleta por parte dos CMRs, conforme observado na Figura 6.

Figura 6. Popular depositando lixo reciclável no tambor e CMRs fazendo a venda do seu produto.

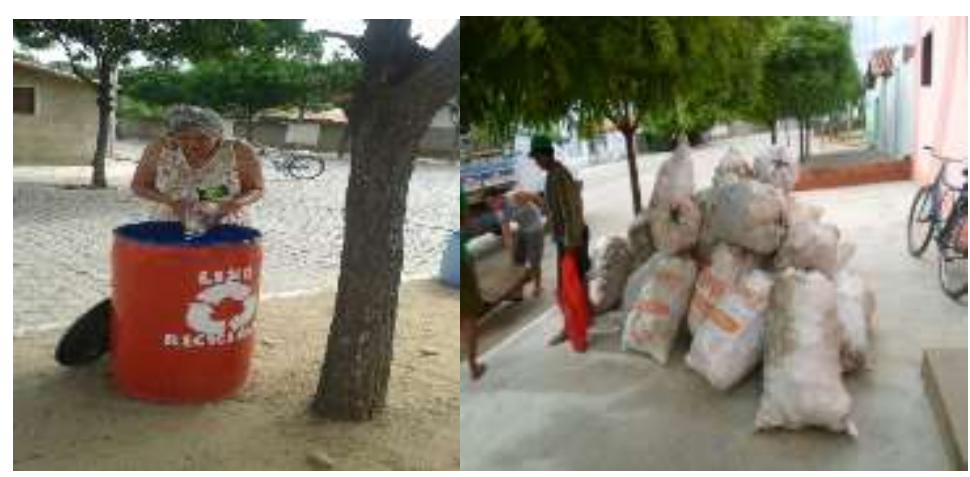

Fonte: Arquivo pessoal dos autores.

Além da geração de renda e da dignificação do trabalho dos CMRs, essas ações são relevantes na economia de recursos públicos gastos com coleta e acondicionamento do lixo. Isso também faz parte das obrigações do ente municipal com relação à conservação ambiental.

O lixo hospitalar é recolhido por empresa especializada para ulterior incineração, tendo em vista poder conter resíduos infectantes ou de risco biológico, como sangue, gazes, curativos e agulhas, como também resíduos especiais, de origem química, farmacêutica e radioativa (Ferreira, 1995). O lixo úmido, formado por restos de alimento, passa por coleta em separado nas residências, coletado por criadores de pequenos animais.

Outra ação de cunho socioambiental implementada na municipalidade a partir do ano de 2017 foi a doação dos resíduos sólidos provenientes de plantas para uma indústria ceramista do município vizinho, Cruzeta/RN. Toda a poda das plantas da cidade, Figura 7, restolho das serralherias e até moveis de madeira descartados, antes recolhidos e queimados, agora são usados na queima de telhas e tijolos, conforme Figura 8. 
Figura 7. Carregamento de poda nas ruas de cidade para uso na queima de telhas e tijolos.

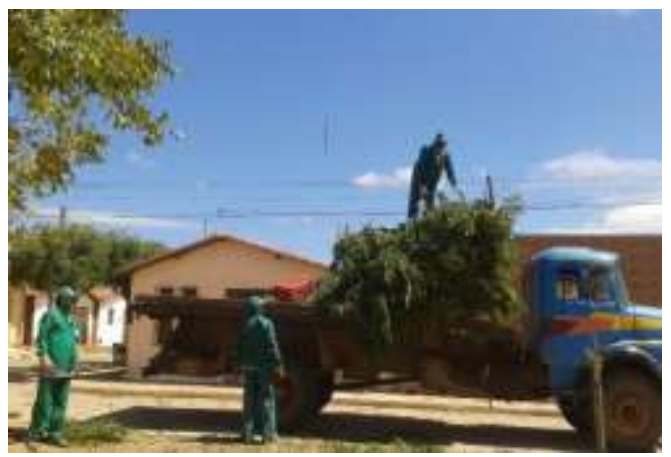

Fonte: Arquivo pessoal dos autores.

Figura 8. Poda das plantas após triturada na máquina para uso nos fornos de queima de telhas e tijolos.

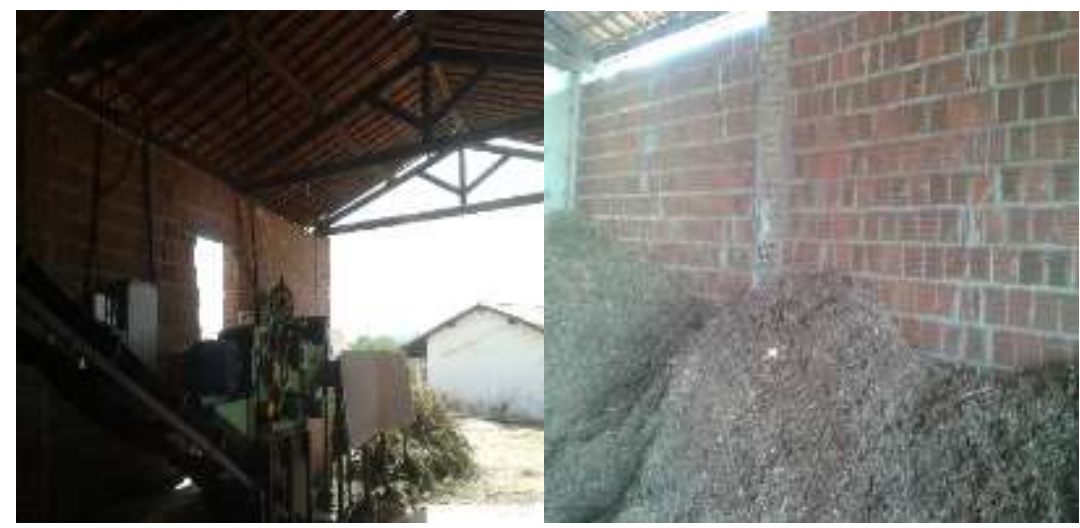

Fonte: Arquivo pessoal dos autores.

Essas ações (aterro controlado, incentivo a coleta seletiva e doação da poda para uso energético) compreendem iniciativas nobres do governo municipal no combate a dois problemas ambientais que ameaçam a sustentabilidade socioeconômica no Semiárido brasileiro, no qual o município faz parte: o processo de desertificação e o aquecimento global. Isso porque quando não se efetua a queima do lixo não se liberam gases de estufa. O uso com fins energéticos da poda das plantas, antes queimada, além dessa relevância tem função emblemática na conservação das plantas do Bioma ${ }^{6}$ Caatinga $^{7}$ que estão sendo poupadas do corte para uso nas cerâmicas.

O conjunto de ações relatadas estão em conformidade com as pretensões contidas no Projeto de Lei do Plano Municipal de Saneamento Básico (PMSB), instrumento de planejamento e política pública compreendendo as ações, metas, programas, e projetos dos serviços públicos municipais de abastecimento de água, esgotamento sanitário, limpeza urbana e manejo de resíduos sólidos, drenagem e manejo de águas pluviais para um horizonte de 20 anos.

\subsection{Relação das Ações Desenvolvidas com os Objetivos da Agenda 2030}

Segundo Rezende (2018), a Agenda 2030 surge de uma reunião de cúpula realizada em 2015 com a presença de representantes de mais de 150 países, na sede da ONU em Nova York. O encontro culminou com a adoção formal da agenda do desenvolvimento sustentável, que se compõe de 17 Objetivos de Desenvolvimento Sustentável (ODS), descritos em detalhe

\footnotetext{
6 "Bioma pode ser definido como um espaço características gráfico cujas características são definidas pelo tipo de clima, vegetação, solo e altitude" (Sena, 2011, p. 07).

${ }^{7} \mathrm{O}$ termo caatinga possui origem Tupi-Guarani e pode ser traduzido como floresta branca, possível referência ao aspecto que a vegetação assume durante o período de seca quando perde suas folhas, sobrando apenas os troncos claros dos arbustos e das árvores na paisagem (Albuquerque \& Bandeira, 1995).
} 
na Tabela 1. Os objetivos foram traçados conforme as cinco áreas consideradas como pilares cruciais para que os ODS possam ser alcançados: pessoas; prosperidade; paz; parcerias; planeta.

Tabela 1. Objetivos de Desenvolvimento Sustentável (ODS).

\begin{tabular}{|c|c|}
\hline Objetivo 01 & Acabar com a pobreza em todas as suas formas, em todos os lugares. \\
\hline Objetivo 02 & Acabar com a fome, alcançar a segurança alimentar e melhoria da nutrição e promover a agricultura sustentável. \\
\hline Objetivo 03 & Assegurar uma vida saudável e promover o bem-estar para todos, em todas as idades. \\
\hline Objetivo 04 & $\begin{array}{l}\text { Assegurar a educação inclusiva e equitativa de qualidade, e promover oportunidades de aprendizagem ao longo } \\
\text { da vida para todos. }\end{array}$ \\
\hline Objetivo 05 & Alcançar a igualdade de gênero e empoderar todas as mulheres e meninas. \\
\hline Objetivo 06 & Assegurar a disponibilidade e gestão sustentável da água e saneamento para todos. \\
\hline Objetivo 07 & Assegurar o acesso confiável, sustentável, moderno e a preço acessível à energia para todos. \\
\hline Objetivo 08 & $\begin{array}{l}\text { Promover o crescimento econômico sustentado, inclusivo e sustentável, emprego pleno e produtivo e trabalho } \\
\text { decente para todos. }\end{array}$ \\
\hline Objetivo 09 & Construir infraestruturas robustas, promover a industrialização inclusiva e sustentável e fomentar a inovação. \\
\hline Objetivo 10 & Reduzir a desigualdade dentro dos países e entre eles. \\
\hline Objetivo 11 & Tornar as cidades e os assentamentos humanos inclusivos, seguros, resistentes e sustentáveis. \\
\hline Objetivo 12 & Assegurar padrões de produção e de consumo sustentáveis. \\
\hline Objetivo 13 & Tomar medidas urgentes para combater a mudança do clima e seus impactos. $\left(^{*}\right)$ \\
\hline Objetivo 14 & $\begin{array}{l}\text { Conservar e usar sustentavelmente dos oceanos, dos mares e dos recursos marinhos para o desenvolvimento } \\
\text { sustentável. }\end{array}$ \\
\hline Objetivo 15 & $\begin{array}{l}\text { Proteger, recuperar e promover o uso sustentável dos ecossistemas terrestres, gerir de forma sustentável as } \\
\text { florestas, combater a desertificação, deter e reverter a degradação da terra e deter a perda de biodiversidade. }\end{array}$ \\
\hline Objetivo 16 & $\begin{array}{l}\text { Promover sociedades pacíficas e inclusivas para o desenvolvimento sustentável, proporcionar o acesso à justiça } \\
\text { para todos e construir instituições eficazes, responsáveis e inclusivas em todos os níveis. }\end{array}$ \\
\hline Objetivo 17 & Fortalecer os meios de implementação e revitalizar a parceria global para o desenvolvimento sustentável. \\
\hline \multicolumn{2}{|c|}{$\begin{array}{l}\text { (*) Reconhecendo que a Convenção Quadro das Nações Unidas sobre Mudança do Clima é o fórum internacional } \\
\text { intergovernamental primário para negociar a resposta global à mudanca do clima. }\end{array}$} \\
\hline
\end{tabular}

Fonte: adaptado da Agenda 2030.

Conforme Cabral, Cabral e Silva (2018), a agenda 2030 se sustenta nos conhecimentos adquiridos e nos progressos conquistados com os 8 Objetivos de Desenvolvimento do Milênio, que esteve em vigência entre os anos 2000 e 2015 . A atual agenda procura encontrar um meio termo e explorar um modelo mundial de erradicação da pobreza e promoção à prosperidade e o bem-estar das populações, com vistas à preservação do meio ambiente e observância as mudanças climáticas.

Os 17 ODS se subdividem em 169 metas para serem alcançadas até o ano de 2030 pelos países que pactuaram da agenda, dentre eles o Brasil. A Tabela 2 apresenta algumas das metas vinculadas aos ODS que o município de São José do Seridó consegue atender com o desenvolvimento de ações voltadas a gestão de resíduos sólidos. 
Tabela 2. Metas associadas aos objetivos da agenda 2030 atendidas pelo município de São José do Seridó.

\begin{tabular}{|c|c|}
\hline Objetivos & Metas \\
\hline Objetivo 04 & $\begin{array}{l}\text { 4.7 Até 2030, garantir que todos os alunos adquiram conhecimentos e habilidades necessárias para promover o } \\
\text { desenvolvimento sustentável, inclusive, entre outros, por meio da educação para o desenvolvimento sustentável e } \\
\text { estilos de vida sustentáveis, direitos humanos, igualdade de gênero, promoção de uma cultura de paz e não } \\
\text { violência, cidadania global e valorização da diversidade cultural e da contribuição da cultura para o } \\
\text { desenvolvimento sustentável. }\end{array}$ \\
\hline Objetivo 08 & $\begin{array}{l}\text { 8.4 Melhorar progressivamente, até 2030, a eficiência dos recursos globais no consumo e na produção, e } \\
\text { empenhar-se para dissociar o crescimento econômico da degradação ambiental, de acordo com o Plano Decenal de } \\
\text { Programas sobre Produção e Consumo Sustentáveis, com os países desenvolvidos assumindo a liderança. }\end{array}$ \\
\hline Objet & $\begin{array}{l}\text { 9.4 Até } 2030 \text {, modernizar a infraestrutura e reabilitar as indústrias para torná-las sustentáveis, com eficiência } \\
\text { aumentada no uso de recursos e maior adoção de tecnologias e processos industriais limpos e ambientalmente } \\
\text { corretos; com todos os países atuando de acordo com suas respectivas capacidades. }\end{array}$ \\
\hline Objet & $\begin{array}{l}\text { 10.2 Até 2030, empoderar e promover a inclusão social, econômica e política de todos, independentemente da } \\
\text { idade, gênero, deficiência, raça, etnia, origem, religião, condição econômica ou outra. }\end{array}$ \\
\hline Objetivo 11 & $\begin{array}{l}\text { 11.6 Até 2030, reduzir o impacto ambiental negativo per capita das cidades, inclusive prestando especial atenção à } \\
\text { qualidade do ar, gestão de resíduos municipais e outros. } \\
\text { 11.a Apoiar relações econômicas, sociais e ambientais positivas entre áreas urbanas, periurbanas e rurais, } \\
\text { reforçando o planejamento nacional e regional de desenvolvimento. }\end{array}$ \\
\hline Objetivo 12 & $\begin{array}{l}\text { 12.2 Até 2030, alcançar a gestão sustentável e o uso eficiente dos recursos naturais. } \\
12.5 \text { Até } 2030 \text {, reduzir substancialmente a geração de resíduos por meio da prevenção, redução, reciclagem e } \\
\text { reuso. } \\
\text { 12.6 Incentivar as empresas, especialmente as empresas grandes e transnacionais, a adotar práticas sustentáveis e a } \\
\text { integrar informações de sustentabilidade em seu ciclo de relatórios. } \\
\text { 12.8 Até 2030, garantir que as pessoas, em todos os lugares, tenham informação relevante e conscientização para o } \\
\text { desenvolvimento sustentável e estilos de vida em harmonia com a natureza. }\end{array}$ \\
\hline Objetivo 13 & $\begin{array}{l}\text { 13.3 Melhorar a educação, aumentar a conscientização e a capacidade humana e institucional sobre mitigação, } \\
\text { adaptação, redução de impacto e alerta precoce da mudança do clima. }\end{array}$ \\
\hline Objetivo 15 & $\begin{array}{l}\text { 15.2 Até 2020, promover a implementação da gestão sustentável de todos os tipos de florestas, deter o } \\
\text { desmatamento, restaurar florestas degradadas e aumentar substancialmente o florestamento e o reflorestamento } \\
\text { globalmente. } \\
15.3 \text { Até } 2030 \text {, combater a desertificação, restaurar a terra e o solo degradado, incluindo terrenos afetados pela } \\
\text { desertificação, secas e inundações, e lutar para alcançar um mundo neutro em termos de degradação do solo. }\end{array}$ \\
\hline
\end{tabular}

Fonte: adaptado da Agenda 2030.

O ODS 04 pode ser atingido por meio do cumprimento da meta 4.7, uma vez que o município realiza ações de conscientização junto a população e estudantes para sensibilização da importância da destinação correta dos resíduos sólidos e das possibilidades de reciclagem de determinados materiais. A difusão do conhecimento e o incentivo ao desenvolvimento sustentável.

Observa-se também a possibilidade do cumprimento da meta 8.4, relacionada ao ODS 08, por meio da melhora gradual da eficiência e reaproveitamento de resíduos, onde parte do material é reciclado, seja para a comercialização pelos CMRs ou para o reaproveitamento na indústria cerâmica, como acontece com os resíduos da poda, o que reduz significativamente os rejeitos sólidos destinados ao aterro controlado.

Visualiza-se que o ODS 09 também possui uma meta atrelada atingida, a meta 9.4, justamente pelo incentivo ao reuso 
dos resíduos de madeira para aproveitamento do potencial calorífico na indústria de cerâmica.

O ODS 10 também pode ser considerado parcialmente atingido, pelo fato de o município incentivar a inclusão social, a geração de emprego e renda por meio do estímulo dado ao trabalho desenvolvido pelos CMRs, como forma de empoderar e promover a inclusão social e econômica dessas pessoas.

No que diz respeito ao ODS 11 é possível notar o envolvimento do munícipio com tal objetivo, uma vez que mediante as ações educativas desenvolvidas em escolas e com os próprios moradores da cidade por meio da conscientização da coleta seletiva é presumível que há uma redução do impacto ambiental negativo per capita da cidade. Além disso, essas ações fazem parte do programa de ações da secretária do meio ambiente do município, que vem a corroborar com o que dispõe a meta 11a do ODS 11.

Constata-se que o ODS 12 está contemplado nas diversas ações apresentadas neste estudo comprovando o comprometimento do município em alcançar uma gestão sustentável e o uso eficiente dos recursos naturais, o que por consequência reduzirá a geração de resíduos sólidos por meio da conscientização da população, coleta seletiva e o uso de resíduos sólidos na indústria ceramista, bem como o aterro controlado que reduzirá o impacto da poluição no ar, no solo e na água. Estas ações incentivam as empresas locais, como é o caso das faç̧ões, uma das principais atividades geradoras de renda da cidade, que adotam parte de restos da sua produção na confecção de almofadas e travesseiros de forma a integrar a sustentabilidade em seu ciclo produtivo. Em meio a essas ações praticadas e incentivadas pela gestão municipal é possível garantir que a sociedade como um todo possa ter informações relevantes e se conscientize sobre o desenvolvimento sustentável.

O ODS 13 é, em parte, atendido pelas ações educativas desenvolvidas em escolas do município por meio de aulas teóricas, práticas e aulas de campo que incentivam os alunos a serem participantes ativos da preservação e sustentabilidade do meio ambiente, por intermédio de incentivo a coleta seletiva dentro e fora das escolas, bem como, do plantio de mudas de plantas nativas e exóticas.

O ODS 15 é atendido de forma parcial, por meio do Projeto Plantar, iniciado em 1997, onde os alunos fazem o plantio de mudas exóticas e nativas promovendo a transformação da área de localização da escola em uma área verde com mais de 100 árvores plantadas, além disso há o reflorestamento de áreas de desertificação com plantio de Faveleiras ${ }^{8}$ promovendo a implementação da gestão sustentável.

\section{Considerações Finais}

Por todo o exposto ao longo da presente pesquisa, pode-se perceber a crescente preocupação com a preservação do meio ambiente por parte dos gestores e da sociedade do município de São José do Seridó, refletida nas diversas ações voltadas à gestão dos resíduos sólidos, como a implantação do aterro controlado, coleta seletiva, ações educativas nas escolas sobre o descarte do lixo, bem como o aproveitamento de podas de árvores pela indústria ceramista da região.

Esse estudo trouxe consigo evidências de que as ações desenvolvidas para a mitigação dos resíduos sólidos apresentam uma preponderante relevância pois reduzem o impacto ambiental, alcançado pelo descarte e aproveitamento adequado dos resíduos sólidos.

Desse modo, constatou-se que a entidade municipal buscou desenvolver atividades aliadas ao comprometimento e responsabilidade sustentável, de maneira que pudesse ocorrer um menor impacto ambiental. Nesse sentido, convém retomar o questionamento formulado em sede introdutória: As ações realizadas pelo município de São José do Seridó/RN estão em

\footnotetext{
${ }^{8}$ Planta nativa do Bioma Caatinga do Nordeste brasileiro, conhecida popularmente como Faveleira ou Favela. Essa planta faz parte da família Euphorbiaceae, decídua, heliófila, pioneira que pode ser encontrada de modo abundante em vários estados do Brasil, como Alagoas, Sergipe, Rio Grande do Norte, Piauí, Bahia, Pernambuco e Paraíba (Morais at al, 2016).
} 
consonância com os objetivos traçados pela Agenda 2030, da Organização das Nações Unidas? (Brasil, 2019)

Tal questão foi solucionada a partir da constatação de que a entidade municipal acata oito dos dezessete ODS, proposto na agenda 2030, mediante desenvolvimento de ações voltadas a gestão de resíduos sólidos no município. É possível correlacionar as ações com oito dos dezessete ODS, proposto na agenda 2030, sendo eles, objetivo 4, 8, 9, 10, 11, 12, 13 e 15. Concluindo-se, portanto, que o município de São José do Seridó/RN é uma entidade gestora comprometida com uma gestão ambiental eficaz, mediante o desenvolvimento de ações corroboradas coma agenda 2030 e que resultam na mitigação dos impactos ambientais e da preservação dos recursos naturais.

Contudo, observou-se a crescente preocupação da sociedade moderna com o desenvolvimento sustentável. Diante disso, novos questionamentos emergem e favorecem o surgimento de investigações científicas, como a possibilidade replicar a presente pesquisa em outros municípios e a chance de expandir o conhecimento com novas indagações, como:

- Quais as mudanças percebidas pela população a partir da adoção de ações que visam atender aos Objetivos do Desenvolvimento Sustentável?

- Como aplicar os princípios contidos nos ODS ao ambiente de negócio das micro e pequenas empresas situadas no interior do semiárido brasileiro?

Dessa forma, essa investigação científica não esgota o leque de possibilidades investigativas nem marca o fim das discussões, pelo contrário permite, através do fornecimento de dados e informações que novas pesquisas se iniciem e sigam o rigor científico necessário. São perguntas de base para futuros trabalhos.

\section{Referências}

Albuquerque, S. G. \& Bandeira, G. R. L. (1995). Effect of thinning and slashing on forage phytomass from a caatinga of Petrolina, Pesquisa Agropecuária Brasileira. 30(6), 885-91.

Almeida, F. F. M., Bhusui, Y., Brito Neves, B. B. \& Fuck, R. A. (1977). Província estrutural brasileira. Atlas VII. Simpósio de Geologia do Nordeste: 363 991.

Barbosa, A. C. (1979). Novo dicionário da língua portuguesa. Egéria.

Benardes, E. (2018). Pesquisa qualitativa em engenharia de produção e gestão de operações. Atlas.

Brasil. (2010). Lei . $^{\circ}$ 12.305/2010 de 2 de agosto de 2010. Institui a Política Nacional de Resíduos Sólidos; altera a Lei no 9.605 , de 12 de fevereiro de 1998; e dá outras providências.

Brasil. (2013). Lixo e saúde: aprenda a cuidar corretamente do lixo e descubra como ter uma vida mais saudável. Funasa.

Brasil (2019). Transformando nosso mundo: a Agenda 2030 para o Desenvolvimento Sustentável. Brasília: Ministério do Meio Ambiente.

Cabral, R. L. G., Cabral, L. C. G., \& Silva, C. G. da. (2018). Promoção de desenvolvimento sustentável no nível municipal: uma análise da dispensa de licitação na coleta seletiva de resíduos frente a agenda 2030. Revista de Direito da Cidade. 10(4), 2736-69

Conke, L. S., \& Nascimento, E. P. do. (2018). A coleta seletiva nas pesquisas brasileiras: uma avaliação metodológica. Urbe. Revista Brasileira. Gestão Urbana, 10(1), 199-212.

Ferreira, J. A. (1995). Resíduos sólidos e lixo hospitalar: uma discussão ética. Cad. Saúde Pública, 11(2), 314-320.

Gil, A. C. (2019). Métodos e técnicas de pesquisa social.. Atlas

Giordano, G., Barbosa Filho, O., \& Carvalho, R. J. (2011). Processos físico-químicos para tratamento do chorume de aterros de resíduos sólidos urbanos.. UERJ.

Gouveia, N. (2012). Resíduos sólidos urbanos: impactos socioambientais e perspectiva de manejo sustentável com inclusão social. Ciência \& Saúde Coletiva. $17(6), 1503-1510$.

IBGE. (2019). Panorama Cidades, IBGE. Acesso em 10 de julho, https://cidades.ibge.gov.br/brasil/rn/sao-jose-do-serido/panorama.

Lisbôa, E. G., Lisbô, É. G., Lobo, M. A. A., Tourinho, H. L. Z., Bello, L. A. L., \& Borges, F. Q. (2020). Aplicação de um modelo Multicriterial para auxiliar a seleção de tecnologias de tratamento de águas residuais em zonas urbanas. Brazilian Journal of Development, 6(4), $20739-20768$.

Maiello, A., Britto, A. L. N. de P., \& Valle, T. F. (2018). Implementação da Política Nacional de Resíduos Sólidos. Rev. Adm. Pública, 52(1), $24-51$. 
Research, Society and Development, v. 10, n. 7, e3410716205, 2021

(CC BY 4.0) | ISSN 2525-3409 | DOI: http://dx.doi.org/10.33448/rsd-v10i7.16205

Matias-Pereira, J. (2019). Manual de metodologia da pesquisa científica. Atlas.

Medeiros, J. B. (2019). Redação científica prática de fichamentos, resumos, resenhas. Atlas.

Medeiros, J. B. (2021). Redação de artigos científicos: métodos de realização, seleção de periódicos, publicação. Atlas.

Morais, N. R. L., Oliveira Neto, F. B., Melo, A. R., Bertini, L. M., Silva, F. F. M., \& Alves, L. A. (2016). Prospecção fitoquímica e avaliação do potencial antioxidante de Cnidoscolus phyllacanthus (müll. Arg.) Pax \& k.hoffm. Oriundo de Apodi - RN. Revista Brasileira de Plantas Medicinais, 18(1), 180-185.

Pereira A. S. et al. (2018). Metodologia da pesquisa científica. UFSM.

Resende, R. M. de C. (2018). A Agenda 2030 e os objetivos de desenvolvimento sustentável nas grandes opções do plano 2017: uma avaliação no contexto de políticas públicas. Dissertação de Mestrado em Engenharia do Ambiente. Lisboa. Universidade Nova de Lisboa.

Santos, M. (1988). Metamorfoses do espaço habitado. Hucitec.

Schueler, A. S. de, Kzure, H., \& Racca, G. B. (2018). Como estão os resíduos urbanos nas favelas cariocas? Rev. Bras. Gest. Urbana, 10(1), $213-230$.

Sena, L. M. M. de. (2011). Conheça e conserve a Caatinga: o bioma Caatinga. Associação Caatinga.

Silva, S. A. da. (2011). Aproveitamento sustentável da borracha proveniente dos pneus usados: ecodesign uma nova abordagem no design de mobiliário urbano. Dissertação de Mestrado em Design Industrial. Porto. Universidade do Porto. 